\title{
Successful endovascular treatment of iatrogenic pseudoaneurysm with a relatively long neck
}

\author{
Masamichi Koganemaru, ${ }^{1}$ Toshi Abe, ${ }^{1}$ Naofumi Hayabuchi, ${ }^{1}$ Kanako Yokoi ${ }^{2}$
}

${ }^{1}$ Department of Radiology, Kurume University School of Medicine, Kurume, Japan ${ }^{2}$ Department of Internal Medicine, Kurume University School of Medicine, Kurume, Japan

\section{Correspondence to} Dr Masamichi Koganemaru, mkoganemaru@med.kurume-u. ac.jp
To cite: Koganemaru $\mathrm{M}$ Abe $\mathrm{T}$, Hayabuchi $\mathrm{N}$, et al. BMJ Case Reports Published online: [please include Day Month Year] doi:10.1136/ bcr-2012-007021

\section{DESCRIPTION}

A 63-year-old man was admitted to our emergency medical centre due to suspected myocardial infarction; coronary angiography was performed via the left common femoral artery. Following cardiac intervention, colour doppler ultrasonography demonstrated left common femoral artery pseudoaneurysm. (CT) revealed a pseudoaneurysm sac (maximum size, $54 \mathrm{~mm}$ ) with a relatively long neck (length, $27 \mathrm{~mm}$; figure 1).

After failed ultrasound-guided compression, left external iliac arteriogram confirmed that the pseudoaneurysm sac communicates via a neck with the left common femoral artery (figure 2A). A 2 Fr-microcatheter was superselectively catheterised into the pseudoaneurysm neck (figure 2B), followed by embolisation by injecting a 1:1 mixture of n-butyl cyanoacrylate (NBCA) and lipiodol to enable fluoroscopic visualisation. Left external iliac arteriogram confirmed complete absence of the pseudoaneurysm immediately after embolisation (figure 2C). Follow-up CT imaging 12 days later revealed no traces of the pseudoaneurysm. Moreover, there were no complications associated with transcatheter embolisation.

Femoral artery pseudoaneurysms occur in $0.2-7.7 \%$ of patients undergoing angiographic procedures. ${ }^{1}$ In general, coil embolisation is an effective treatment at sites both distal and proximal to the pseudoaneurysm. ${ }^{2}$ However, in the present case, the technique may have caused lower limb

\section{Competing interests None.}

Patient consent Obtained.

Provenance and peer review Not commissioned; externally peer reviewed. direct percutaneous embolisation.

\section{Learning points} complication of angiography. relatively long neck. ischaemia. Treatment options for pseudoaneurysm include ultrasound-guided compression and direct percutaneous thrombin injection. ${ }^{3} \mathrm{NBCA}$ is a liquid embolic material, and the adhesion time can be flexibly adjusted according to the rate of mixed lipiodol. A distinct advantage of NBCA in lipiodol is its dense radiopacity; as the exact site of occlusion can be observed during the embolisation procedure. NBCA undergoes rapid polymerisation and solidification and provides permanent embolisation; hence, migration of the embolic material can be prevented. The present technique demonstrated that superselective embolisation of the pseudoaneurysm neck was possible without the need for

- latrogenic pseudoaneurysm is an undesirable

- Endovascular treatment for pseudoaneurysm should be effective, particularly with a

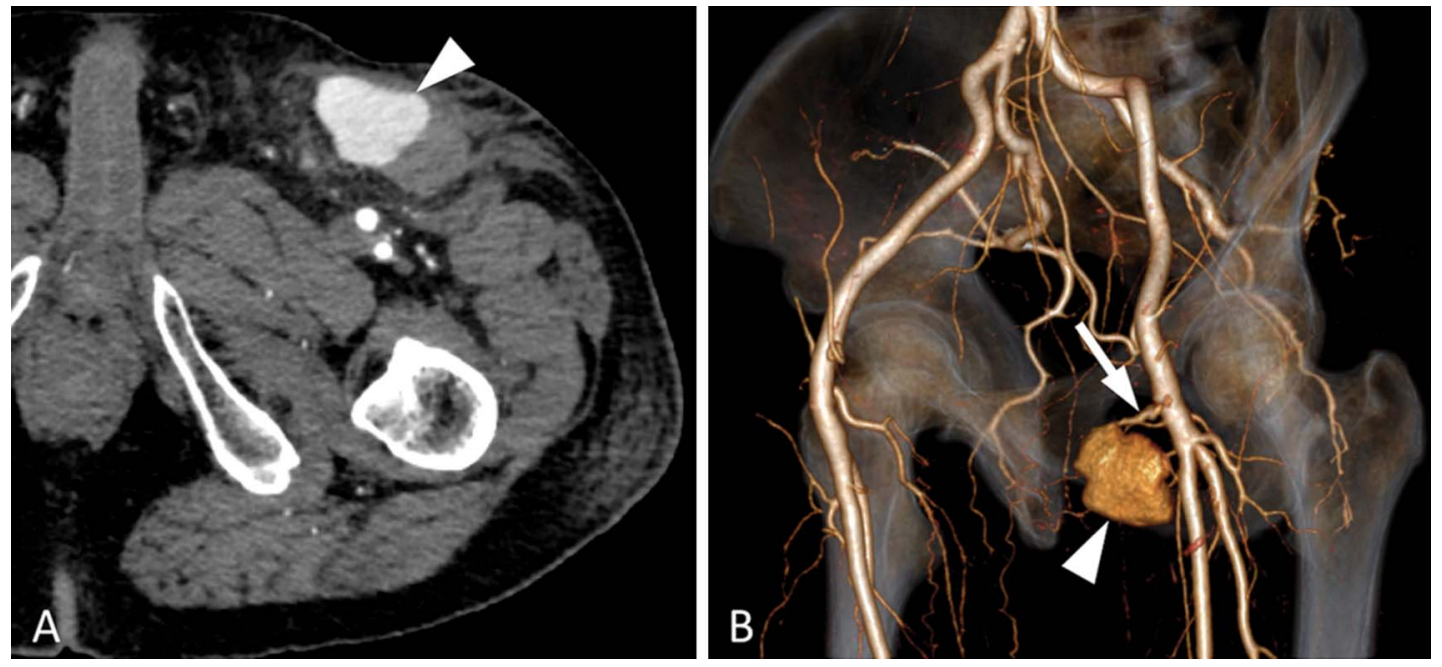

Figure 1 Contrast-enhanced CT in the arterial phase revealed a well- enhanced area (arrowhead) in the left inguinal region (A). Three-dimensional CT revealed a common femoral artery pseudoaneurysm (arrowhead) with a relatively long neck (arrow) (B). 

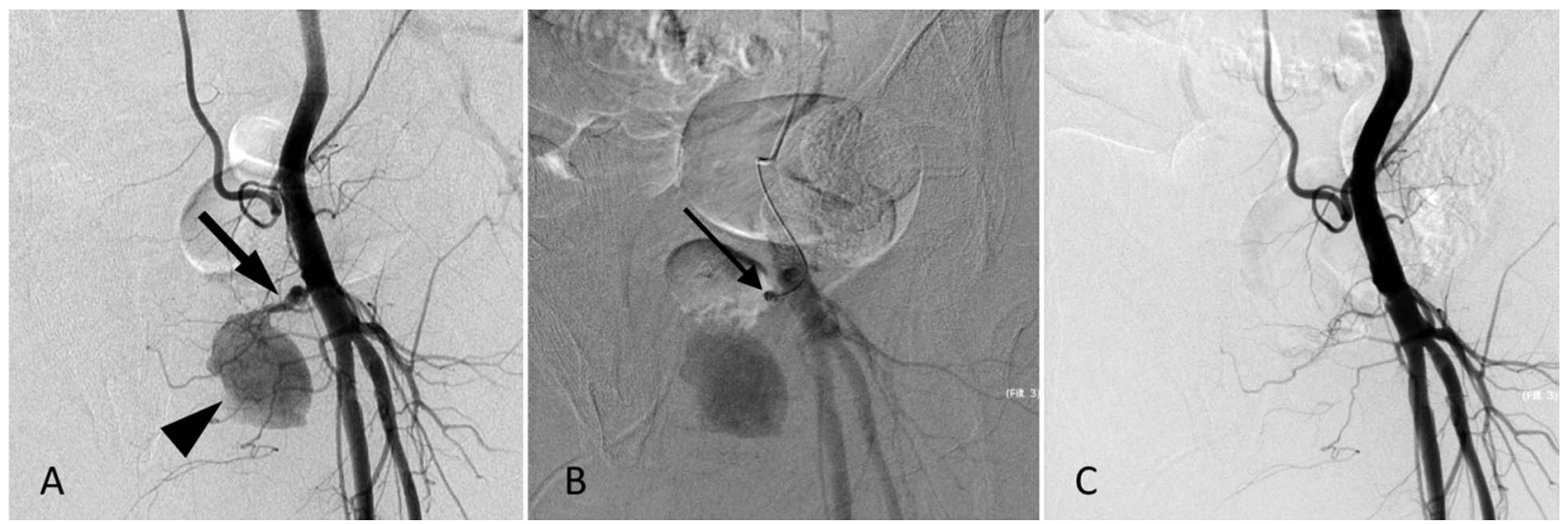

Figure 2 Left external angiogram revealed a pseudoaneurysm sac (arrowhead) and neck (arrow) (A). A microcatheter was superselectively catheterised into the pseudoaneurysm neck (thin arrow), followed by embolisation injecting a mixture of n-butyl cyanoacrylate and lipiodol (B). Left external iliac arteriogram immediately after embolisation confirmed complete absence of the pseudoaneurysm (C).

\section{REFERENCES}

1 Nakai $\mathrm{M}$, Sato $\mathrm{M}$, Sanda $\mathrm{H}$, et al. Percutaneous fluoroscopically guided $\mathrm{n}$-butyl cyanoacrylate (NBCA) injection for iatrogenic femoral arterial pseudoaneurysm under temporary balloon occlusion of arterial blood flow. Jpn J Radiol 2012;30:365-9.

2 Ikeda O, Nakasone Y, Tamura Y, et al. Endovascular management of visceral artery pseudoaneurysms: transcatheter coil embolization using the isolation technique. Cardiovasc Interv Radiol 2010;33:1128-34.

3 Chatterjee T, Do DD, Kaufmann U, et al. Ultrasound-guided compression repair for treatment of femoral artery pseudoaneurysm: acute and follow-up results. Cathet Cardiovasc Diagn 1996;38:335-40.

Copyright 2013 BMJ Publishing Group. All rights reserved. For permission to reuse any of this content visit http://group.bmj.com/group/rights-licensing/permissions.

BMJ Case Report Fellows may re-use this article for personal use and teaching without any further permission.

Become a Fellow of BMJ Case Reports today and you can:

- Submit as many cases as you like

- Enjoy fast sympathetic peer review and rapid publication of accepted articles

- Access all the published articles

- Re-use any of the published material for personal use and teaching without further permission

For information on Institutional Fellowships contact consortiasales@bmjgroup.com

Visit casereports.bmj.com for more articles like this and to become a Fellow 